Invest. pens. crit. (ISSN 1812-3864)

Vol. 5, No. 1, enero-abril 2017

pp. 77-95

\title{
Fraude Académico: nueva industria de la educación universitaria globalizada
}

\author{
Etilvia M. Arjona-Tseng, Ph.D. \\ Investigadora \\ Centro de Estudios de la Educación Superior (CEDUSMA) \\ Universidad Católica Santa María La Antigua \\ Panamá, Rep. De Panamá \\ Email: targum@icloud.com
}

Recibido: 03 de abril de 2017

Aceptado: 10 de abril de 2017

\begin{abstract}
Resumen ejecutivo
Con este trabajo buscamos alertar a la comunidad universitaria de nuestro país a las particularidades de esta nueva industria, ofrecer un modelo que detalla las complejas transacciones que ocurren durante el cruce transfronterizo de información académica así como una escala de gradación sobre el concepto de fraude académico. Presentaremos varios casos inauditos recientes que muestran la gravedad del tema. Finalizaremos el capítulo examinando ciertos casos que muestran posible ambigüedad en el mercadeo de la oferta en el sistema universitario panameño. Estos casos resaltan la necesidad que existe en el país de tener un ente regulador de la actividad que se da en el sector universitario. Asimismo hacen estos casos evidente el hecho de que nuestra Academia debe dejar, lo antes posible, su monolingüismo e internacionalizarse para potenciar su competitividad y resguardar su buen nombre.
\end{abstract}

Palabras Clave: Globalización, fraude académico, educación universitaria, academia, calidad, acreditación.

\begin{abstract}
With this work we seek to alert the academic community of our country on the particularities of this new "industry", as well as to offer a model that details the complex transactions that occur during the cross-border of academic information as well as a gradation scale on the concept of academic fraud. We will present several recent unprecedented cases that show the seriousness of the issue. We will conclude by examining certain cases that show possible ambiguity in the marketing of supply in the Panamanian university system. These cases highlight the need in the country to have a regulator of the activities that occur within the local university sector. Likewise, these cases make evident the fact that our Academy must, as soon as possible, abandon its monolingualism and internationalize itself, in order to enhance its competitiveness and protect its good name.
\end{abstract}

Keywords: Globalization, academic fraud, university education, academia, quality, accreditation. 
Invest. pens. crit. (ISSN 1812-3864)

Vol. 5, No. 1, enero-abril 2017

pp. $73-95$

La globalización de la educación universitaria conlleva una serie de ventajas y oportunidades para toda universidad que desee cumplir con su misión educativa. La internacionalización de la educación universitaria abre ventajosas posibilidades de movilidad para su personal educando, administrativo y docente pero también abre jugosas posibilidades para negociados académicos. Hoy día la Academia global se ha constituido, à la MacLuhan, en una aldea global, aldea cuya 'manera de hacer negocios' solo es inteligible mediante análisis multilingües y multiculturales por personal debidamente especializado en lo pertinente a la cultura universitaria nacional e internacional.

La rapidez de las comunicaciones, las increíbles facilidades informáticas disponibles, el creciente interés en obtener credenciales académicas y la mayor aceptación de la educación a distancia son unas cuantas de las razones por las cuales una corriente fraudulenta está tomando vertiginosamente fuerza en el sistema universitario global. La sociedad en general y los estudiantes en particular necesitan que el anhelado aseguramiento de la calidad cubra, de manera vigilante, todos los aspectos de la oferta académica que se mercadea.

La figura a continuación detalla los componentes (regulación, estructuras, créditos, planes de estudios, gobierno universitario, etc.) que deben considerarse cada vez que una información académica cruza el sistema universitario de un estado a otro, de una lengua a otra. La información que cruza puede tomar la forma de un diploma, título, plan de estudio o calificaciones obtenidas.

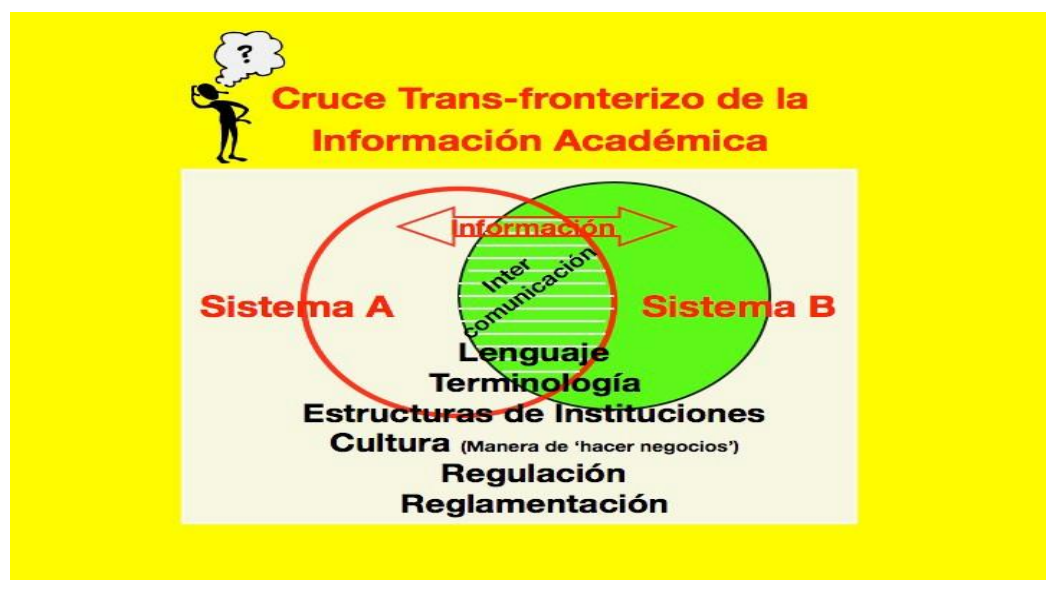

Un ejemplo sencillo de este cruce transfronterizo lo tenemos en el vocablo bachiller que, solamente en Centro América, puede referirse a un egresado de los niveles secundarios, preuniversitarios o de pre-grado. ¡Y, esto sin haber cambiado de lengua! El proceso de Bolonia añade a esta terminología su propia complicación al definir bachiller como el egresado de un ciclo universitario de estudios cuya duración es de tres años - y utilizado por unos cuarenta y tanto países con idiomas distintos al nuestro.

Otro ejemplo común lo tenemos en la información suministrada en sitios web institucionales. O, 
Invest. pens. crit. (ISSN 1812-3864)

Vol. 5, No. 1, enero-abril 2017

pp. $77-95$

mejor todavía, en los correos electrónicos que recibimos casi a diario con ofertas sobre magníficas oportunidades de superación personal en universidades con nombres impresionantes y posibilidades casi irresistibles. ¿Cómo sabemos si esta institución está acreditada? ¿Es fidedigna? ¿Otorga títulos aceptados internacionalmente? El asunto se complica cuando esta información se encuentra en un idioma desconocido. En este caso, ¿a dónde o a quién debemos recurrir? Y, ¿es de confiar la persona, la institución o la agencia a la cual recurrimos para que nos clarifiquen nuestra duda?

Podría ser que nuestro problema no sea más que un problema de terminología. Pero ¿cuáles son lo límites semánticos de vocablos como universidad, educación superior, institución educativa, etc.?

Qué entendemos por fraude, o mas bien, fraude académico?

¿Según los códigos pertinentes, qué constituye un fraude académico? Cuándo hablamos de fraude académico, ¿qué queremos decir? Somos culpables:

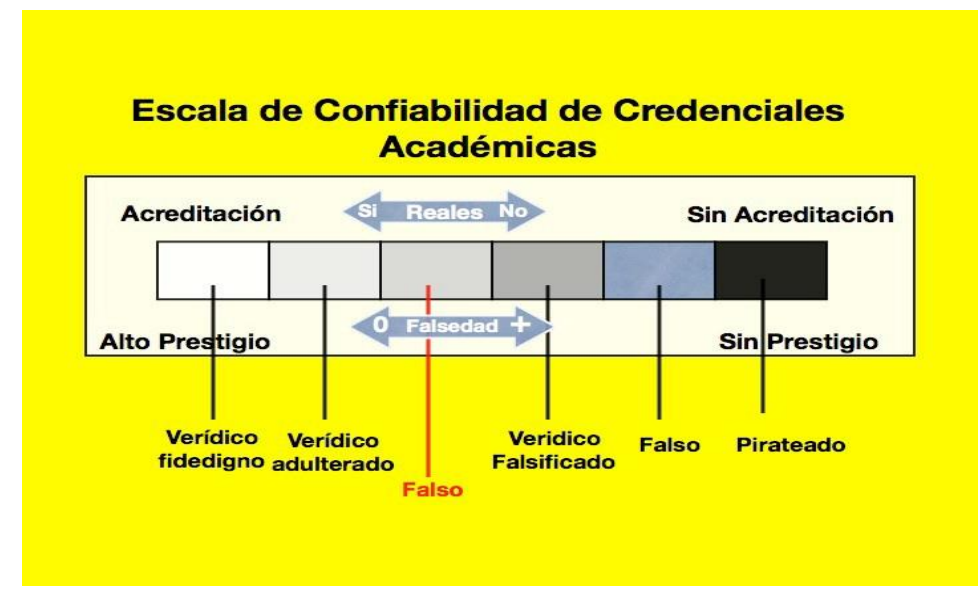

- ¿Al hacernos/dejarnos llamar doctor/magíster/licenciado sin ostentar título alguno?

- ¿Al hacer cambiar una nota en un boletín escolar?

- ¿Al ejercer una profesión sin la debida idoneidad o estudios académicos?¿Al comprar un diploma de una universidad acreditada? $\mathrm{O}$ ¿de una universidad no acreditada? $\mathrm{O}$ ¿de una universidad inexistente?

- ¿Al comprar un título de una universidad acreditada? $\mathrm{O}$ ¿de una universidad no acreditada? $\mathrm{O} \dot{\mathrm{d}} \mathrm{de}$ una universidad inexistente? $\mathrm{O} \dot{\mathrm{d}} \mathrm{de}$ una agencia que imprime replicas exactas de diplomas?

$\circ \quad ¿ A l$ vender un título profesional por dinero? ¿al regalar un diploma falso?

- ¿Al vender un título de médico, ingeniero, oncólogo, arquitecto, abogado, terapeuta, profesor universitario, psicólogo, obispo?

○ ¿Al sustentar nuestro ascenso laboral con credenciales y créditos comprados? 
Invest. pens. crit. (ISSN 1812-3864)

Vol. 5, No. 1, enero-abril 2017

pp. $73-95$

El cuadro anterior resalta la complejidad del asunto ya que nos muestra la sutíl gradación que puede existir entre lo fiable y fidedigno y lo que comienza por ser dudoso y termina siendo un fraude que una sociedad no puede tolerar.

\section{La oferta de credenciales fraudulentas}

Nadie duda de los beneficios que el internet y la informática traen a nuestra vida cotidiana, profesional o académica. Sin embargo, todo dueño de una cuenta de correo electrónico sabe que hoy no es inusual que por lo menos un 5\% de nuestro correo electrónico contenga tentadoras ofertas sobre credenciales académicas rápidamente obtenibles en los más variados sitios web en diversos países, o mediante una simple llamada telefónica a variados números suministrados en el correo recibido.

Nos informa este amigable sitio:

Si no domina el idioma inglés, no se preocupe más, ahora nació diplomashispanos.com;

El propósito de nuestro servicio, es que quienes estén altamente calificados, logren alcanzar un Título de Grado o Postgrado en reconocimiento a su capacitación emitido por Universidades legales y reconocidas.

En la descripción de la oferta nos aseguran que por unos meros 1,500 euros podremos obtener:

1. Entrega a nivel mundial,

2. Envío porcorreo privado con número de reconocimiento, la transcripción del programa que sustenta el título, con el desglose de las asignaturas, créditos, duración, etc.

3. La legalización en origen,

4. El envío certificado de los documentos, y finalmente

5. Un título universitario de maestrías o doctorado.

¿Le preocupa la calidad de esta oferta o su aval académico? ¡No tiene por qué! -

diplomashispanos.com le asegura que

‘transformamos su experiencia de vida en créditos académicos... Su currículo más un proyecto de carrera le dan acceso a su Grado Universitario avalado por la UNESCO.” 
Invest. pens. crit. (ISSN 1812-3864)

Vol. 5, No. 1, enero-abril 2017

pp. $77-95$

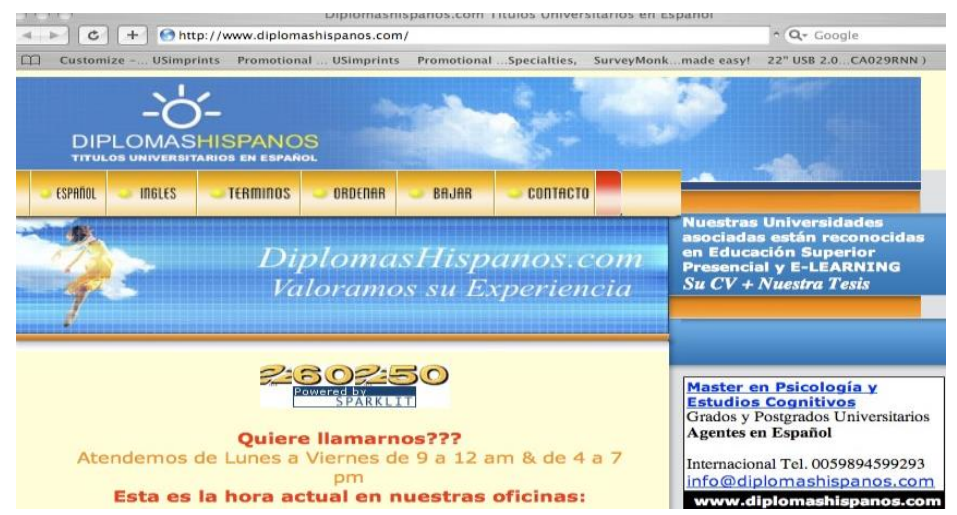

Esta nueva industria se caracteriza, principalmente, por su extenso ámbito geográfico. Una búsqueda en Internet presenta listados de sitios web con ofertas en todos los idiomas, todos los continentes y en países tales como, Argentina, Cuba, China, Guatemala, Colombia, Ecuador, México, Panamá, Rusia, Canadá, Francia, etc.

Igualmente de vasto es el listado de especialidades ofrecidas: ingeniería aeronáutica, derecho, epidemiología, química medicinal, embriología, tecnología radiológica, medicina osteopática, cirugía plástica, salud pública, cirugía ortopédica, oncología, etc..., es más, si no encuentra la especialidad deseada, muchos sitios web le ofrecen gentilmente fabricársela sin costo adicional.

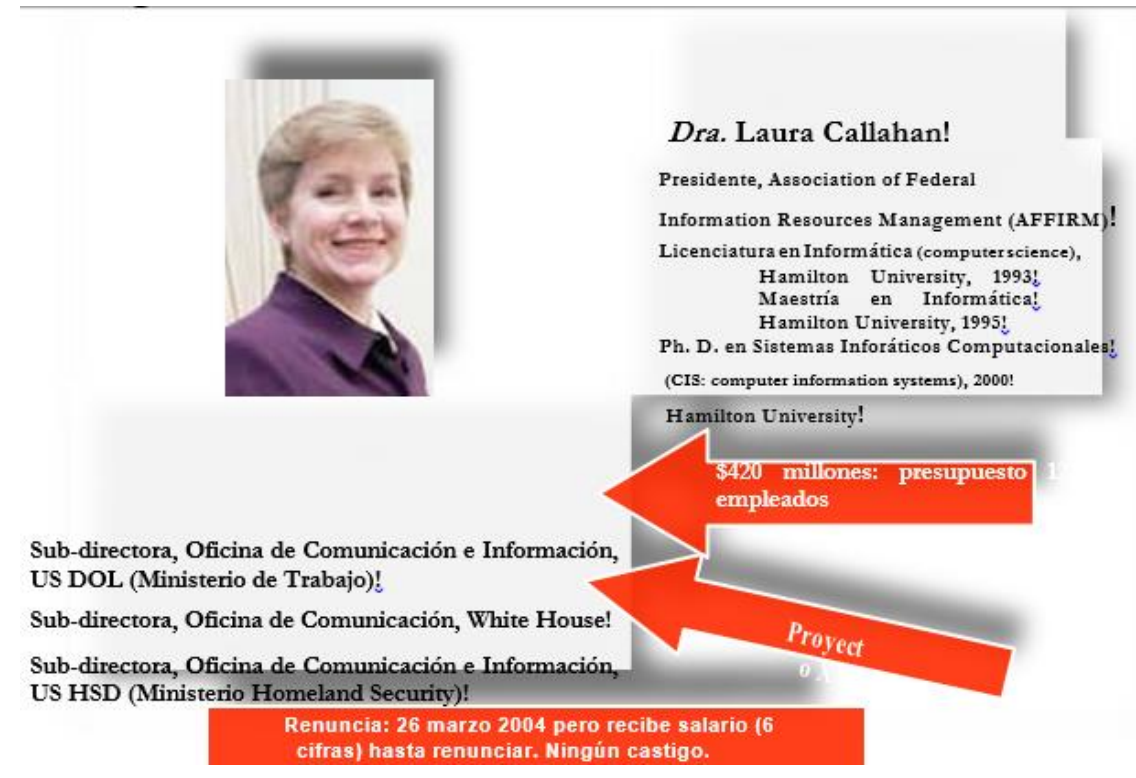

No es de extrañar entonces, que casos inauditos aparezcan en los medios de comunicación, a medida q u e p e r s o n a s responsables se interesen por desenmascarar lo que bien podemos denominar la epidemia académica de la era $d G$ (después de la Globalización). 
Invest. pens. crit. (ISSN 1812-3864)

Vol. 5, No. 1, enero-abril 2017

pp. $73-95$

Es así como nos enteramos de que la Dra. Laura Callahan, directora del Departamento de Informática, Tecnología y Comunicación de la Casa Blanca y del Departamento de Homeland Security basó un envidiable currículo laboral en una serie de diplomas y grados emitidos por Hamilton University, reconocida universidad fabricante de diplomas.

No menos inquietante es la noticia de que la Dra. Marilee Jones, decana de Admisiones en el Massachusetts Institute of Technology (MIT), institución mundialmente reconocida, basó su trayectoria profesional en varios grados inexistentes ya que: "licité empleo en MIT hace 28 años y no tuve el valor necesario para corregir mi currículo cuando apliqué para mi posición actual o en ninguna otra instancia.".

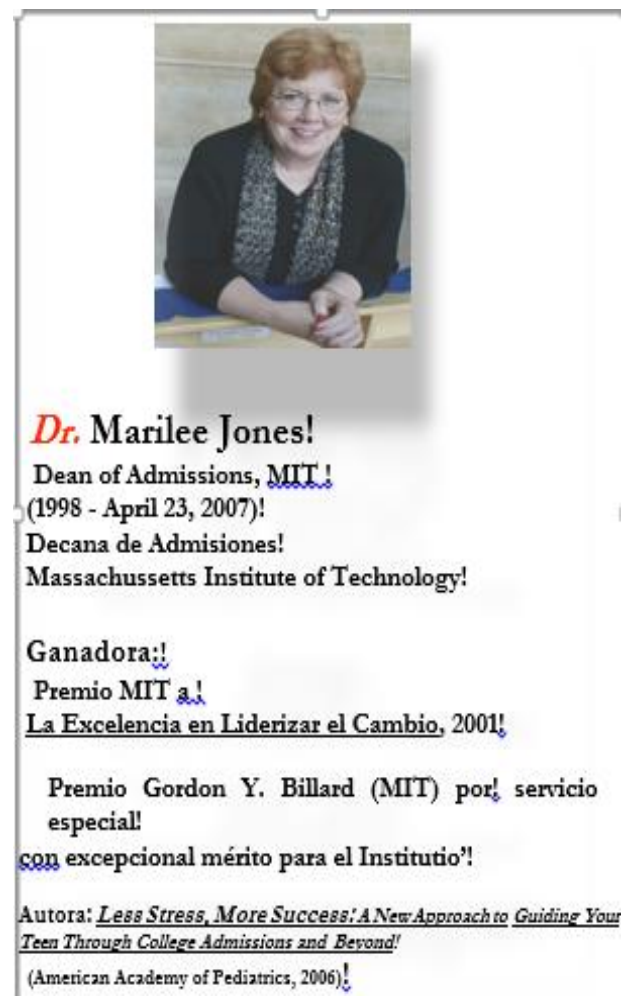

El mundo académico global está desarrollando actualmente la infraestructura necesaria para una cultura de aseguramiento de la calidad así como para la acreditación institucional y programática de instituciones universitarias. Es importante reconocer que un universo paralelo ${ }^{1}$ está igualmente surgiendo con la creación de agencias y comisiones de acreditación y aseguramiento de calidad cuestionables, que dan un manto de validez y credibilidad al mundo de instituciones especializadas en fabricar diplomas ficticios y credenciales académicas fraudulentas. Frecuentemente, los mismos dueños de las universidades ficticias establecen agencias de acreditación ${ }^{2}$ que son igualmente ficticia o dudosas. La idea es presentarle al incauto, o al interesado, un paquete completo de servicios a la venta: créditos, escritos, asesoramiento, diplomas, certificaciones, idoneidad, cátedras, la lista es casi infinita. 
Invest. pens. crit. (ISSN 1812-3864)

Vol. 5, No. 1, enero-abril 2017

pp. $77-95$

Un ejemplo conocido es el de Maxine Klein Arsher ${ }^{3}$, presidenta de la World Education Accrediting Commission (WOEAC) ${ }^{4}$ y el Board of Online Universities Accreditation (BOUA). Estas agencias ofrecen un servicio completo desde la acreditación de universidades como Ashwood University, la reconocida fábrica de diplomas investigada por el Dr. Gollin, hasta las universidades tipo vanity ${ }^{5}$ descrita posteriormente.

Ashwood University no titubeó en otorgarle el doctorado (Ph. D.) a Félix Bombay ${ }^{6}$, gato favorito del investigador que se propuso desenmascar la oferta de esa institución. Claro está que ni lo sagrado se escapa de esta nueva industria académica, como lo comprobó el Ilustrísimo y Reverendísimo Dr. Edgard St. Patrick McQuaid, obispo, quien siempre anheló llegar a la santidad y decidió iniciar dicho camino comprando un obispado.

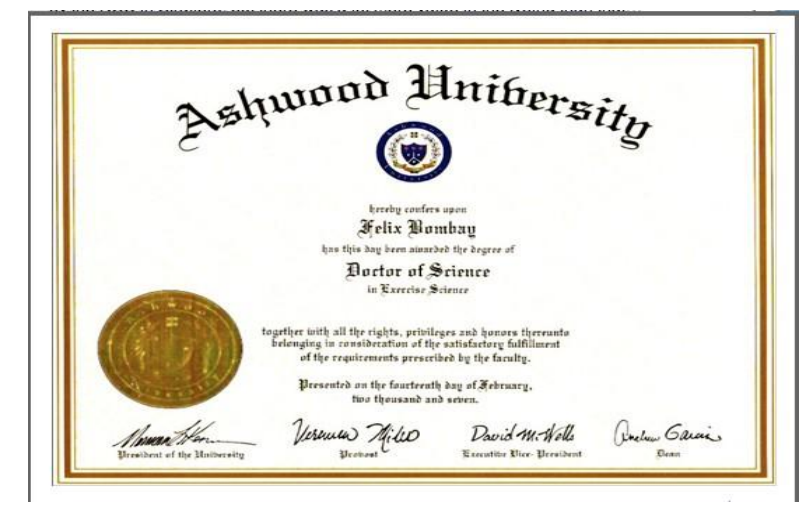

Otro aspecto inquietante de esta industria cubre tanto a universidades que son de renombre mundial como a las que tienen nombres que no son fácilmente reconocidos. En ambos casos es difícil reconocer el fraude, por falta de familiaridad con el sistema universitario del país o estado de origen o por problemas de idioma.

Un anuncio en la web reza de la siguiente manera:

Need a degree from Harvard, Yale, Stanford, or MIT? No problem. Send us a Check!

¿Necesita un título de Harvard, Yale, Stanford o MIT?

¡No se preocupe! ¡Envíenos un cheque!

La investigadora principal de este estudio, al tener ya un doctorado de Stanford, decidió ver cuán facil era obtener otro de una de las más reconocidas universidades en el género: Belford University. La duración del doctorado tardó exactamente siete minutos, tiempo suficiente para establecer impecables crédenciales vivenciales ${ }^{7}$ que le merecieron un grado summa cum laude. Siendo conocida por sufrir de una aerofobia aguda, se escogió la aeronáutica como la menos probable profesión. La respuesta congratulatoria no se hizo esperar y a vuelta de correo electrónico (previa verificación de la Visa) se le informó sobre la futura entrega de los documentos doctorales en el correo de Miami. 
Invest. pens. crit. (ISSN 1812-3864)

Vol. 5, No. 1, enero-abril 2017

pp. 73-95

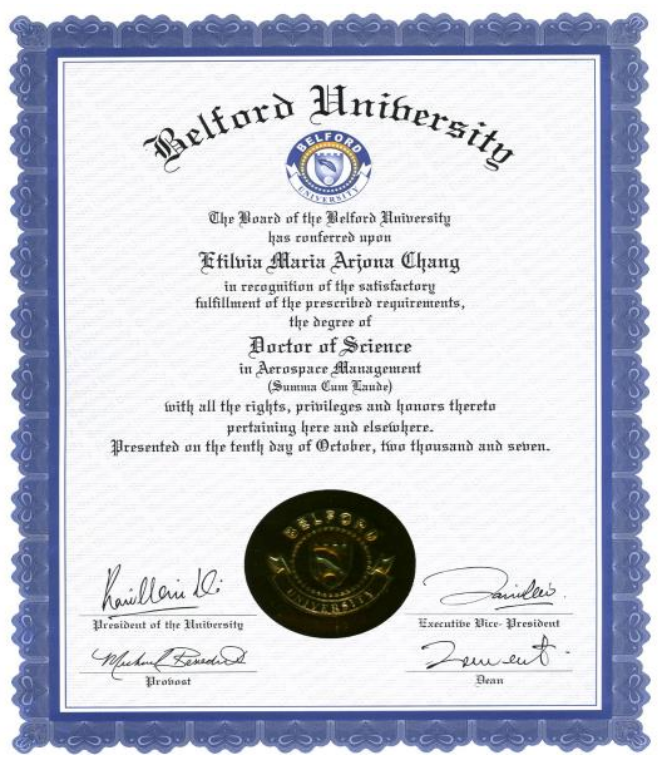

La llegada del diploma tardó un poco más que la sustentación académica ya que, por razones de seguridad, se estableció entrega del paquete en dos diferentes países.

\section{Dimensiones de la nueva industria}

$\mathrm{El}$ auge en instituciones universitarias de dudosa competencia aumenta hoy vertiginosamente gracias al incremento en el uso de la informática. Literalmente, no existe campo del conocimiento alguno que se le escapa: salud pública, gobierno, académico, urbanístico, la lista no tiene fin.

La preocupación por la seguridad ciudadana está comenzando a hacer mella y aumenta el número de reportajes en los medios alertando al público en general de la amenaza existente y de la urgencia por legislación que clarifique los términos y defina las sanciones requeridas. Un reportaje reciente nos formula esta inquietante pregunta:

Los sitios web que ofrecen diplomas y títulos falsos o de dudosa validés se cuentan en millares. La oferta cubre desde la impresión de diplomas de las más prestigiosas universidades del mundo hasta la fabricación de una identidad en el registro institucional y el suministro de un set completo de credenciales y créditos fraudulentos!

Frecuentemente ignoramos la oferta recibida en nuestros correos con una sonrisa o, quizás, un poco de enojo por la molestia causada. ¡Definitivamente, este problema no nos atañe! ¡Tenemos cosas más importantes en qué ocuparnos! 
Do you know where your doctor, lawyer, or clergyman earned his or her degree? In 1986, a congressional committee report concluded that "more than 500,000 working Americans have a fraudulent degree." The media hardly noticed. The public yawned. The academic world buried its head in the sand. and things have gotten much, much worse since then."

¿Sabe Ud. dónde obtuvo su grado académico su doctor, abogado, o pastor? En 1986, un estudio de un comité del congreso estadounidense determinó que "más de 500,000 trabajadores estadounidenses tienen grados académicos fraudulentos." Los medios apenas tomaron nota. El público bostezó. El mundo académico hizo lo del avestruz y enterró su cabeza en la arena. Y las cosas han empeorado mucho, mucho más desde entonces.

El 14 de noviembre de 2007 la autora principal de este informe presentó una charla sobre fraude académico durante la II Sesión Ordinaria del Consejo Centroamericano de Acreditación de la Educación Superior (CCA). Era esta charla un primer llamado de atención a la comunidad universitaria centroamericana sobre la necesidad de poner el fraude académico y su control en la agenda del CCA y de las entidades encargadas de garantizar el aseguramiento de la calidad en el mundo académico

Escasamente un mes después, a mediados de diciembre de 2007, durante un viaje a la frontera México/Estados Unidos en busca de un tratamiento médico para un familiar enfermo de gravedad pude constatar, en plena vista en la clínica visitada, dos diplomas de doctorado en medicina de universidades caribeñas investigadas por las autoridades estadounidenses y declaradas de dudosa validez. ${ }^{8}$ No es fácil trasmitir esta clase de información a una familia en busca de un milagro médico como el que el tal especialista prometía!

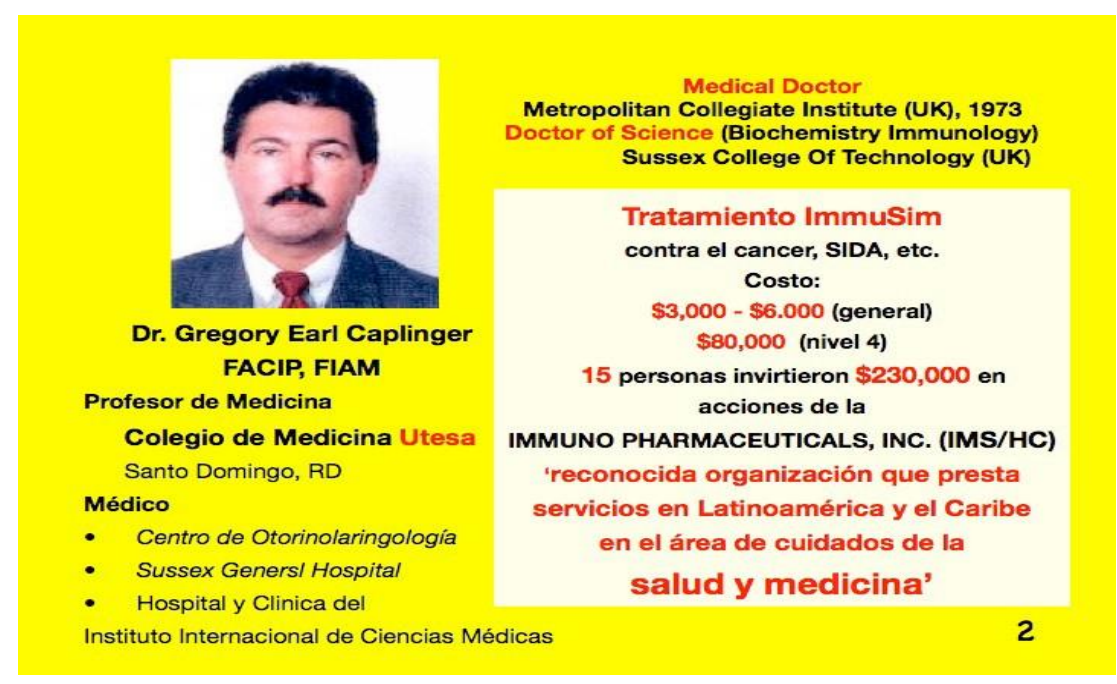

La misma autora al participar como jurado en la selección de futuros becarios de la SENACYT para estudios doctorales en el extranjeros, becas que podían ascender a mas de US\$250,000, constató, con 
Invest. pens. crit. (ISSN 1812-3864)

Vol. 5, No. 1, enero-abril 2017

pp. $73-95$

igual sorpresa, durante la entrevista final, que entre las credenciales presentada por una concursante se encontraba un diploma emitido por una fábrica de diplomas de reciente injerencia en territorio panameño y que había recibido notoriedad en la prensa nacional. La falta de información al respecto había impedido que se reconociera la documentación fraudulenta.

\section{¿Cómo ponerle cascabel al gato?}

La globalización educativa y el actual énfasis en la movilidad estudiantil y profesional conllevan importantes retos a la comunidad universitaria mundial. De imperiosa necesidad es el desarrollo de mecanismos informativos que nos permitan acceder a información fidedigna sobre estructuras académicas, sistemas universitarios, acreditación institucional y programática, aseguramiento de la calidad, credenciales académicas, etc..

Es necesario poder vencer, entre otras dificultades, las causadas por las diferencias lingüísticas que nos impiden saber si una credencial presentada en idioma que no es el oficial o nacional es, en realidad, válida y fidedigna, o, por lo menos, poder efectuar una apreciación adecuada de los documentos presentados. El fraude académico es tema prioritario para la agenda de la academia universitaria internacional, centroamericana y panameña ${ }^{9}$

\section{La metodología Gollin, DIPSCAM, y Operación Gold Seal ${ }^{10}$}

George Gollin, catedrático y profesor de física en la Universidad de Illinois, tiene años de llevar a cabo una campaña personal desenmascarando a los principales actores en la industria del fraude académico. Una técnica utilizada por el profesor Gollin para desenmascarar a los culpables es la de establecer si la institución existe en realidad. La pesquisa se inicia buscando verificar si la dirección suministrada en la página web es verdadera y si en realidad los gráficos utilizados pertenecen a la universidad que se investiga. Al investigar una universidad llamada Ashland University en Londres.

De esta manera se pudo comprobar que tanto los retratos del 'campus' institucional como la dirección física eran inexistentes o pertenecían a otra institución reconocida. Las figuras 5 y 6 en la siguiente página nos muestran lo que encontró al investigar la dirección física de una connotada fábrica de diplomas, la Ashwood University en Londres.

\section{DIPSCAM y Operación Gold Seal}

Los casos Callahan y MIT anteriormente discutidos llevaron a la FBI y a congresistas estadounidenses a iniciar una serie de investigaciones que han tenido como resultado el reciente enjuiciamiento de destacados direigentes de esta creciente industria.

Cabe notar sobretodo el enjuiciamiento del imperio Randock ${ }^{11}$. Según Gollin, cubrían una gama extensa de disciplinas académicas, la cual se ve en el cuadro que se presenta a continuación para así tener una idea de lo que solo UNA de estas compañías puede abarcar 


\section{Cuadro 14. Titulaciones vendidas por St. Regis University, por campo disciplinario}

\begin{tabular}{|c|c|c|c|c|c|c|c|c|}
\hline Carrera & Тес & Lic & MA & Doc & Prof & Cert & Total & $\%$ \\
\hline $\begin{array}{l}\text { Negocios, finanzas, } \\
\text { manufactura y comercio }\end{array}$ & 29 & 1463 & 882 & 299 & 27 & 67 & 2767 & 40.2 \\
\hline $\begin{array}{l}\text { Salud, incluye medicina y } \\
\text { ciencias del } \\
\text { comportamiento }\end{array}$ & 8 & 279 & 195 & 226 & 20 & 32 & 760 & 11.0 \\
\hline Educación & 11 & 183 & 140 & 151 & 11 & 20 & 516 & 7.5 \\
\hline $\begin{array}{l}\text { Ingeniería, arquitectura, } \\
\text { ciencias computacionales } \\
\text { y tecnología }\end{array}$ & 19 & 811 & 360 & 128 & 24 & 26 & 1368 & 19.0 \\
\hline $\begin{array}{l}\text { Derecho y justicia } \\
\text { criminal }\end{array}$ & 16 & 372 & 99 & 40 & 8 & 5 & 439 & 6.4 \\
\hline $\begin{array}{c}\text { Ciencias físicas y } \\
\text { biológicas }\end{array}$ & 82 & 43 & 22 & 10 & 0 & 1 & 158 & 2.3 \\
\hline Teología y religion & 3 & 51 & 51 & 77 & 6 & 10 & 197 & 2.9 \\
\hline Artes y humanidades & 5 & 51 & 33 & 61 & 6 & 2 & 157 & 2.3 \\
\hline $\begin{array}{ll}\text { Ciencias } & \text { sociales, trabajo } \\
\text { social, } & \text { periodismo e } \\
\text { historia } & \end{array}$ & 0 & 202 & 116 & 79 & 4 & 8 & 409 & 5.9 \\
\hline $\begin{array}{l}\text { Seguridad pública, } \\
\text { gerencia ambiental, } \\
\text { planificación urbana }\end{array}$ & 3 & 65 & 35 & 9 & 2 & 3 & 117 & 1.7 \\
\hline Totales & 176 & 3419 & 1933 & 1080 & 106 & 174 & 6888 & 100 \\
\hline
\end{tabular}

Gracias al operativo Gold Seal ${ }^{12}$ del Servicio Secreto estadounidense se pudo desenmascarar esta organización que llegó a controlar una embajada, el ministerio de educación de un país y establecer los cimientos de un sistema educativo universitario completo que, supuestamente, estaba amparado oficialmente por un país africano ${ }^{13}$.

\section{Gollins y sus colaboradores: ¿posible solución a la desinformación internacional?}

Esta inquietante resultante de la globalización educativa ha alcanzado tal proporción que diferentes estados comienzan a tomar medidas para sancionar a los infractores y suministrar información a la sociedad en general. El Dr. Gollin y Alan Contreras ${ }^{14}$ del estado de Oregón han promovido el 
Invest. pens. crit. (ISSN 1812-3864)

Vol. 5, No. 1, enero-abril 2017

pp. 73-95

establecimiento de sitios webs que contienen listados de instituciones y agencias no acreditadas así como de casos pendiente en tribunales estadounidenses. Varios países han establecidos sitios webs donde la persona interesada puede consultar listas ${ }^{15}$ de instituciones que trafican en este negocio. En el anexo de este informe se incluye una lista de estos sitios webs establecidos por diferentes países y agencias donde se presentan informaciones variadas sobre agencias e instituciones universitarias ficticias o no reconocidas.
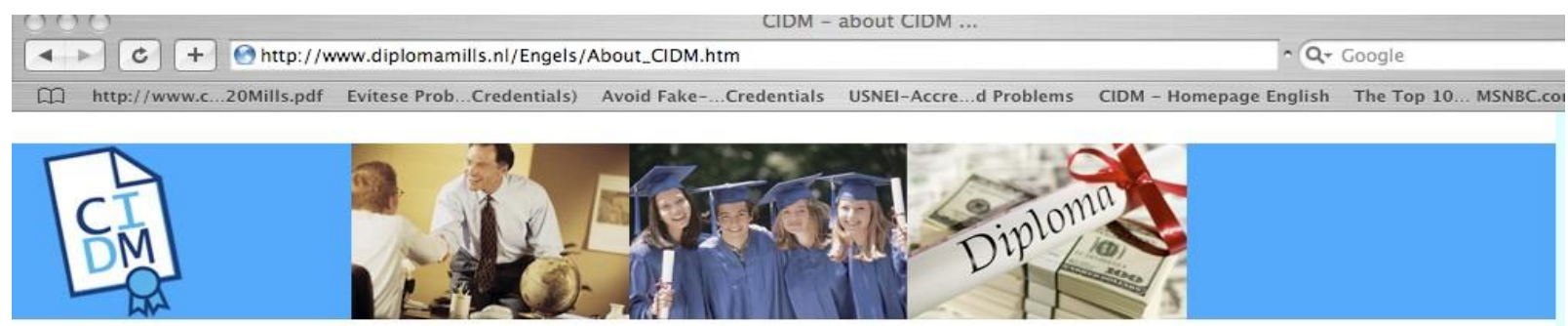

ABOUT CIDM

The Centre for Information on Diploma Mills is a joint activity of the Informatie Beheer Groep

(Agency for International Educational Credential Recognition and Legalization) and Nuffic (Centre

for International Recognition and Certification ), by order of the Netherlands Ministry of Education,

Culture and Science.

\section{El caso de acuerdos internacionales}

Para Panamá definiciones de particular interés aparecen en los últimos escritos del Dr. Gollin y de Allan Contreras en los cuales estos investigadores definen dos importantes conceptos: estas definiciones ${ }^{16}$ cubren los términos (1) degree mill y (2) diploma mill; y a la vez lanzan una voz de alerta sobre los procedimientos usados por este tipo de instituciones de dudosa honorabilidad cuando internacionalizan su oferta y se convierten en operarios transnacionales o transfronterizos.

Debemos entender como fábrica de títulos (degree mill) aquella institución que ofrece un título 'verídico' de una institución falsa (fake). Por fábrica de diplomas (diploma mill) debemos entender una institución que ofrece un título falso de una universidad real. Este problema terminológico se complica en extremo al tratar de establecer ¿qué es una universidad real? Específicamente, en Panamá, qué es 'una universidad'? La institución a la cual el Ministerio de Educación le ha otorgado permiso para operar? ¿o la que aparece en el listado de la Universidad de Panamá? ¿o la que se registra como sociedad mercantil en el Registro Público de Panamá? ¿o la que firma un acuerdo con una institución aprobada, fiscalizada o registrada en Panamá? ¿Quién le otorga a dicha institución la autorización de otorgar títulos o grados académicos? El creciente número de 'universidades' registradas en nuestro Registro Público, de por sí, debe constituir una inquietud para la Academia fidedigna panameña.

Pero, Gollin y Contreras lanzan otra voz de alerta; en este caso sobre la posibilidad que existe para que se den variados tipos de negociados dentro de la educación universitaria transnacional. La TNE, 
Invest. pens. crit. (ISSN 1812-3864)

Vol. 5, No. 1, enero-abril 2017

pp. $77-95$

de por si complicada por factores lingüísticos y socioculturales, presenta un reto para los estados. ¿Cómo podemos asegurarnos que la credencial que se origina en un país que no es el nuestro es fidedigna? ¿Qué pasa cuando una institución reconocida oficialmente en un país ofrece títulos o credenciales que provienen de una institución extranjera fraudulenta o de dudosa ejecutoria?

Un ejemplo dado en el último escrito de Gollin y Contreras aclara la manera en que esto es posible mediante 'acuerdos internacionales' entre instituciones que operan en diferentes países. Citan ${ }^{17}$ el caso de una institución acreditada regionalmente que ofrece credenciales por intermedio de un programa europeo que es manejado desde un sótano por un proveedor de servicios sin autoridad para otorgar títulos universitarios.

Algo parecido parece ser factible en Panamá. En el transcurso de este estudio hemos recibido solicitudes del extranjero preguntándonos si ciertas instituciones universitarias operan en Panamá dada la dificultad en encontrar un listado oficial actualizado. Recientemente, varias solicitudes nos han hecho investigar instituciones panameñas que se proyectan internacionalmente. Todas las instituciones, aparecen debidamente inscritas en el Registro Civil y aparecen en listados de muchos de los sitios web sobre universidades en Panamá.

\section{West Coast University, Inc.}

La primera institución, West Coast University, Inc. nos presenta impresionantes pruebas de sus variadas acreditaciones. Lo inusual es la manera de presentar estas excepcionales certificaciones. En la siguiente página se presenta la carta de reconocimiento que ostensiblemente le permite otorgar títulos a dicha institución. Una ligera búsqueda en el Internet presenta señales inquietantes sobre el pedigree $^{18}$ de esta institución que, sin embargo, puede proclamar al mundo que es una universidad debidamente registrada como tal en nuestro Registro Público y con permisos para otorgar todo tipo de titulaciones. Al investigar la procedencia del certificado de acreditación que postulan se encuentra uno con una posible vinculación con la St. Regis University anteriormente discutida en este informe.

Otra solicitud nos llevó al sitio web de la Universidad de Cartago. Nos llamó la atención en este caso la información presentada sobre importantes acuerdos internacionales que dicha institución estaba efectuando. Saltó inmediatamente a la vista el pedigree ofrecido por la entidad firmante de un acuerdo con la entidad panameña que anuncia lo siguiente:

Convenio de Evaluación de los Títulos de nuestra institución por la California University del estado de California, Estados Unidos de América.

El 16 de abril de 2007, la California University aceptó el convenio con nuestra institución para evaluar nuestros títulos universitarios y homologarlos y emitir títulos de los Estados Unidos de América. 
Invest. pens. crit. (ISSN 1812-3864)

Vol. 5, No. 1, enero-abril 2017

pp. $73-95$
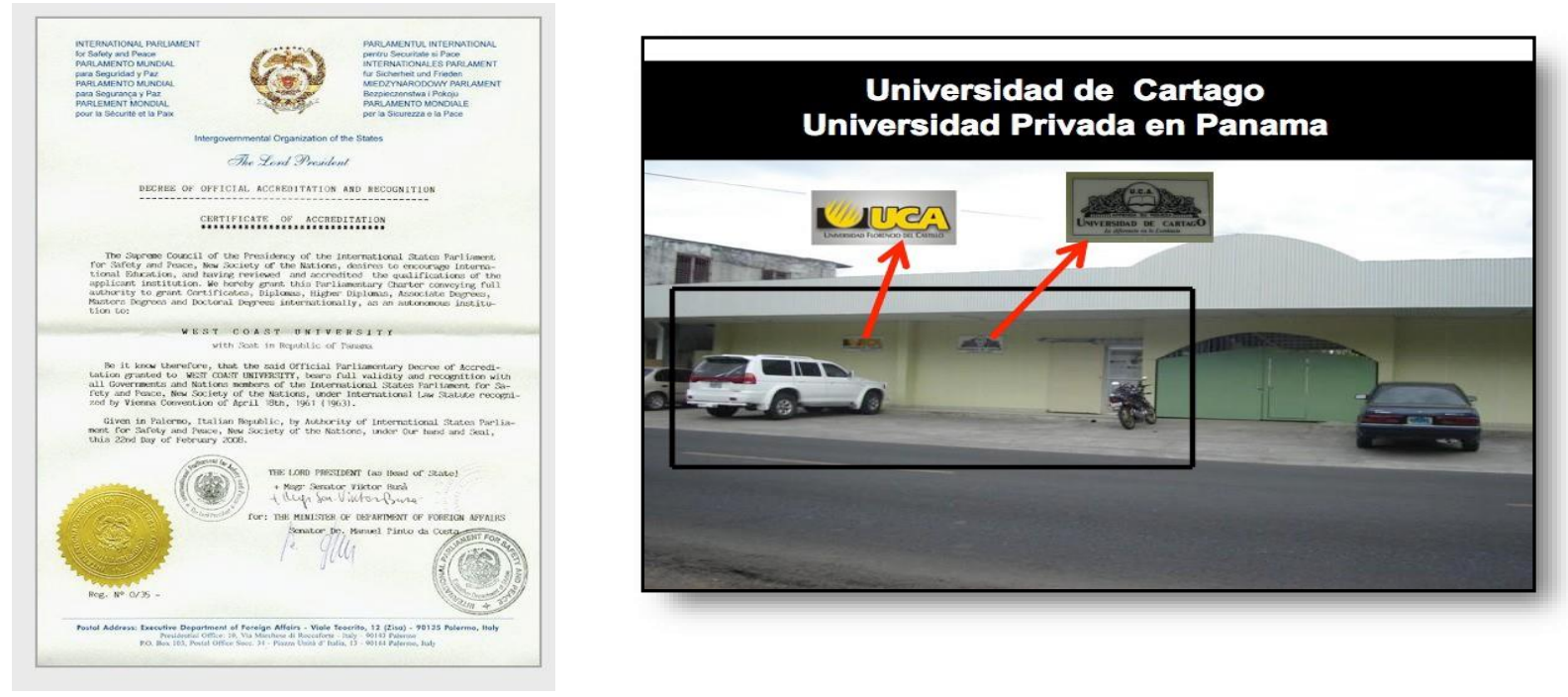

Nos preguntamos si la institución panameña, cuyo rector anuncia en su carta de bienvenida que la

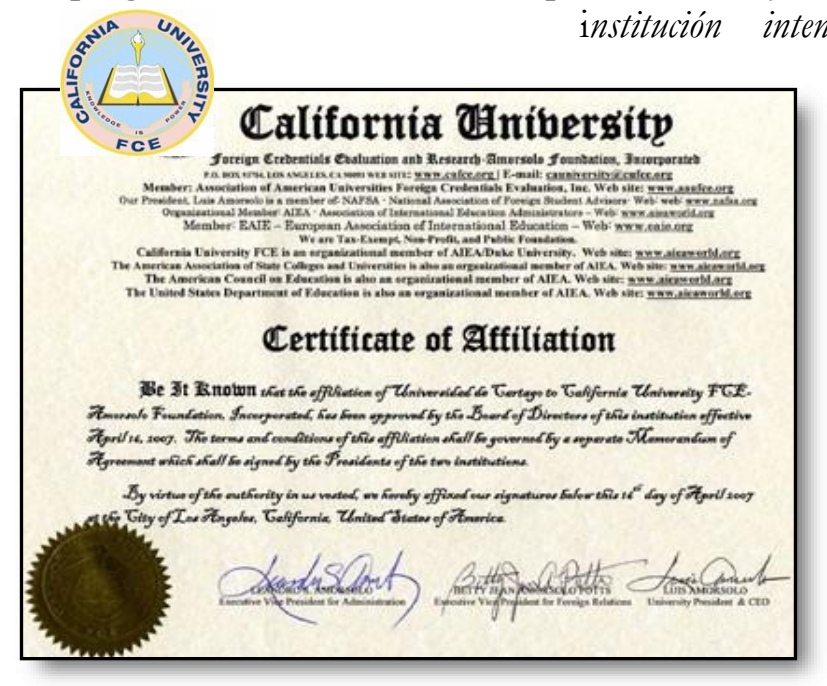

títulos de los Estados Unidos.

buscar activamente acuerdos transnacionales ha investigado California University. La American Association

of Collegiate

Registrars and Admissions Officers (AACRAO) confirma nuestra sospecha sobre el status de dicha Universidad, lo cual nos lleva a profundizar la búsqueda de información en la internet. En realidad California University FCE resulta no ser más que un servicio de certificación de credenciales registrado como una fundación ${ }^{19}$ (FCE $=$ Foreign Credential Evaluation and Research Amorsolo Foundation, Inc.). Cabe notar la interesante oferta que proclama el acuerdo firmado con la entidad panameña: evaluar nuestros títulos universitarios y homologarlos y emitir

Puesto que el registro comercial de dicha fundación no cubre la autorización para otorgar títulos o grados académicos debemos asumir que aquellas personas que deseen homologar sus credenciales y recibir un título otorgado por California University (que no no debe confundirse con ninguna institución afiliada al sistema universitario del estado de California) solo lo requieren para fines de inmigración a dicho país.

Otra consulta, recibida de la AACRAO, muy recientemente, nos solicita informarle sobre la validez de una institución llamada Universidad Central de Enfermería Ashdod que solo presenta un 
apartado postal y se anuncia como una institución universitaria hebrea sin fines de lucro. A pesar de intensas búsquedas en el Registro Civil y consultas con personas del gremio y en la considerable documentación que tenemos sobre el sector universitario en Panamá no hemos podido establecer la verdadera existencia de una institución que, aparentemente, se proyecta

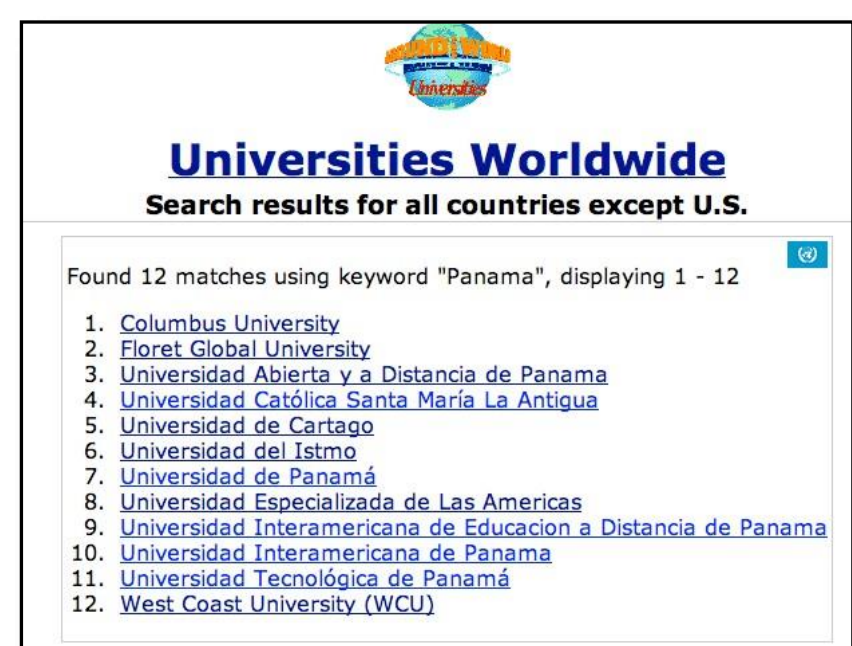

Home - World Listing - United States - Add Link - Help internacionalmente al punto de tener interacción con la asociación estadounidense de secretari os ge ne rale s universitarios.

La extrema flexibilidad ofrecida por el sistema actual para otorgar permiso para operar una universidad en Panamá permite un sinnúmero de posibilidades de oferta que quedan lejos de prestarle al consumidor la debida seguridad. Para terminar, informamos sobre dos ejemplos investigados que muestran claramente la fiscalización inexistente de nuestro sistema universitario.

\section{La Floret Global University}

El sitio web de Universities Worldwide se basa en el World List of U n i v e r s i t i e s q u e publicaba la International Universities Association (IUA). Por ser una lista que muchas de las instituciones de dudosa validez utilizan hicimos una búsqueda y encontramos no solo la West Coast University sino otra que nos llamó la atención por no encontrarse en los listados que se había investigado para este estudio. La Floret Global University aparece debidamente registrada en el Registro Público según ellos mismos indican en su sitio web. Alegan tener licencia del Ministerio de Comercio e Industrias para ofrecer programas de grado a distancia con cobertura mundial. Lo interesante del caso es que la oferta cubre asimismo un Ph. D. (doctorado) que, escuetamente, se ofrece mediante un simple registro.

El título, según Floret Global University, se otorga previa licencia otorgada por el Ministerio de Comercio e Industrias, lo cual significaría que tenemos otra modalidad de entrada al sistema de oferta universitaria panameño.

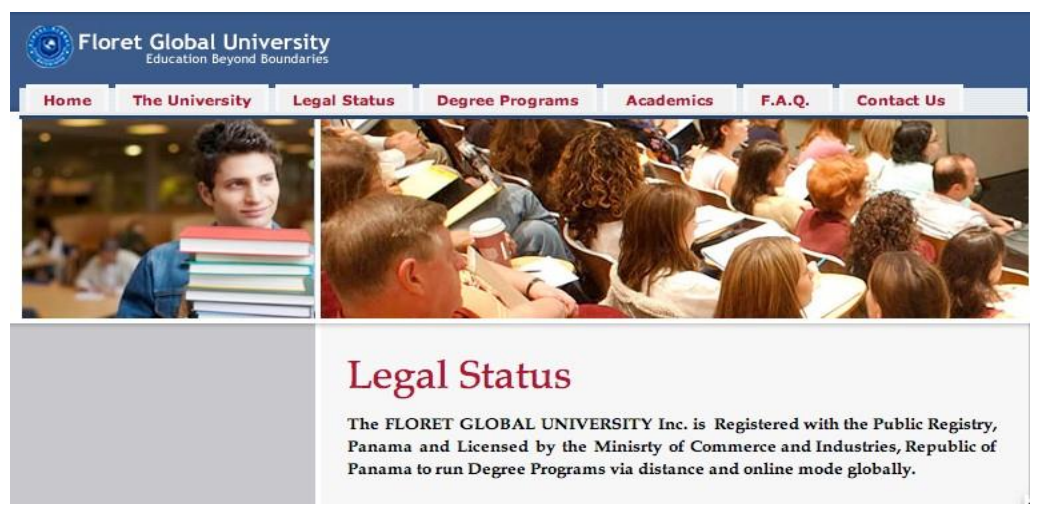


Invest. pens. crit. (ISSN 1812-3864)

Vol. 5, No. 1, enero-abril 2017

pp. $73-95$

ADEN, Universidad de Alta Dirección (UAD)
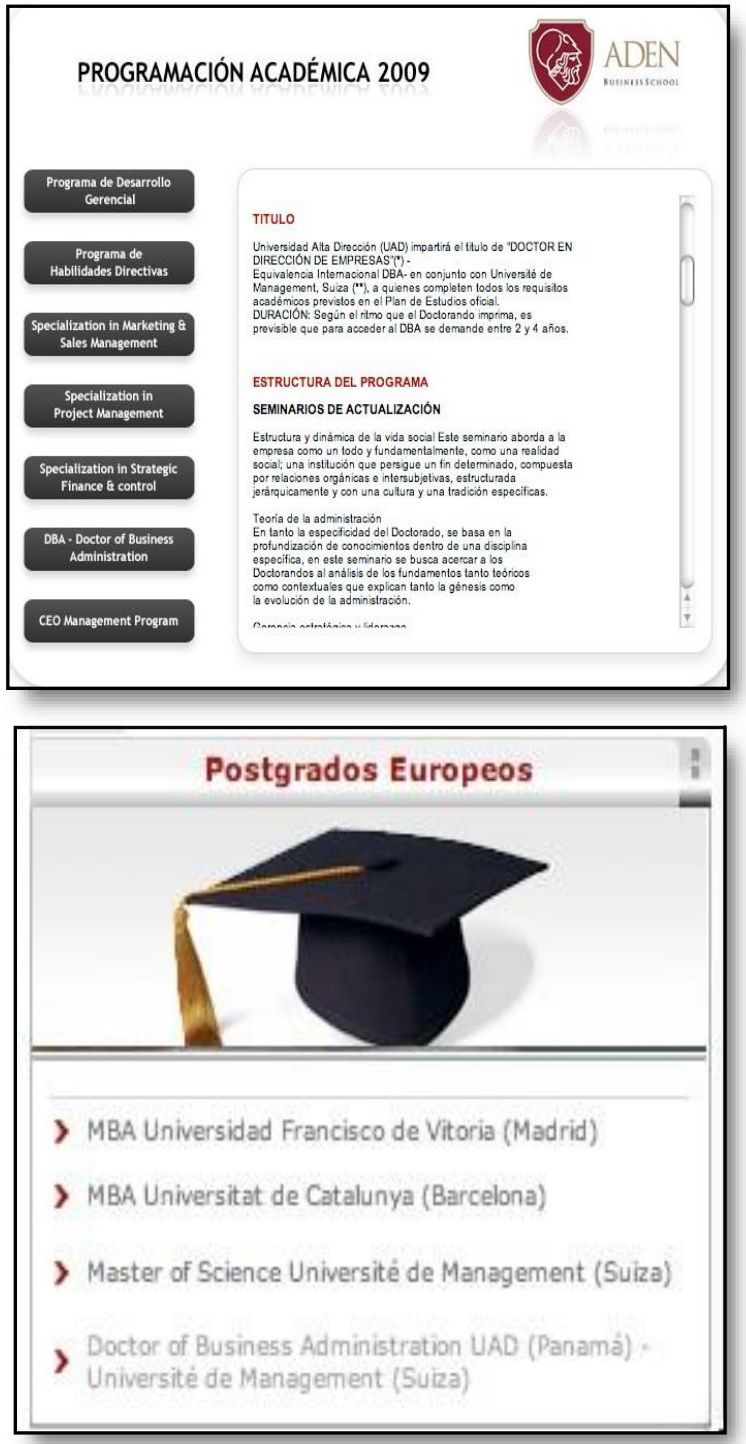

El sitio web de la Universidad de Alta Dirección ubicada en la Ciudad del Saber anuncia que impartirá el título de Doctor of Business Administration (UAD) en conjunto con Université de Management (Suiza) a 'quienes completen todos los requisitos académicos previstos en el Plan de Estudios oficial. Un primer y pequeño asterísco hace el señalamiento de que el Doctor en Dirección de Empresas otorgado por la Universidad de Alta Dirección es 'un titulo no oficial en el país del cursado (sic) a ser emitido en Panamá. Un segundo asterisco doble hace una salvedad similar al señalar que la Equivalencia Internacional DBA, otorgada en conjunto con Université de Management, Suiza es 'un título no oficial en el país de cursado (sic) a ser emitido en Suiza'.

Surgen dos preguntas: primero, ¿qué valor puede tener esta titulación? y, segundo, ¿quién fiscaliza la veracidad de la información presentada en los sitios webs de nuestras universidades?

El tema del fraude académico está tomando cuerpo de manera tan vertiginosa que como hemos visto los estados han comenzado a tomar cartas en el asunto. En los EE. UU. diez estados ${ }^{20}$ han aprobado leyes que establecen que el uso de una credencial o título 
Invest. pens. crit. (ISSN 1812-3864)

Vol. 5, No. 1, enero-abril 2017

pp. $77-95$

fraudulento es ilegal. Sin embargo, un estado conocido por su excelencia académica, California, es el único en permitir que cualquiera pueda otorgar una titulación. (Contreras y Gollin, 2009).

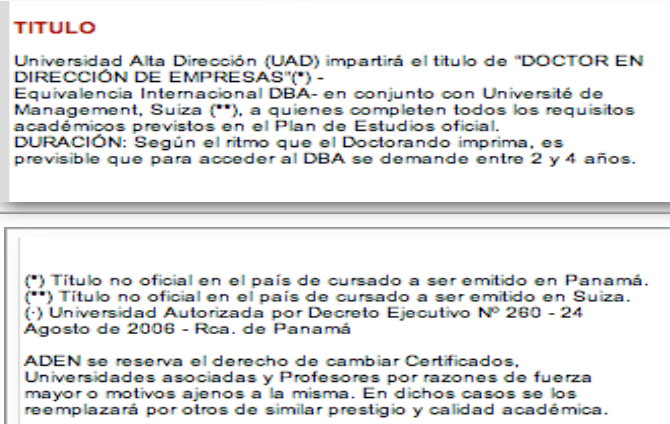

Preocupa la mención frecuente de Panamá en la literatura especializada sobre este tema. Dado la facilidad y flexibilidad conocida de nuestro sistema de incorporación mercantil este tema adquiere una importancia especial. El crecimiento desbocado de instituciones 'universitarias' en Panamá debe ser controlado, regulado y frenado.

Una verdadera globalización de la educación universitaria, con la consiguiente internacionalización y transnacionalización del sistema nacional universitario, no puede tomar su curso positivo sin que un verdadero aseguramiento de la calidad sea instituido y respaldado por una voluntad política con miras a darle a la sociedad panameña el sistema universitario que se merece.

Este estudio espera haber presentado información útil para futuros estudios del sistema universitario panameño, la globalización universitaria y sus efectos en la internacionalización de nuestras universidades. Panamá requiere de una competitividad educativa que surta el acervo en recursos humanos que requiere para continuar su papel de país prestatario de servicios internacionales de calidad.

Asimismo, esperamos haber sonado una voz de alerta a los problemas que requieren tanto una atención inmediata de nuestra clase universitaria dirigente como nuestra participación activa y comprometida a nivel de la Academia internacional. 
Invest. pens. crit. (ISSN 1812-3864)

Vol. 5, No. 1, enero-abril 2017

pp. $73-95$

\section{Notas}

1 Este escrito se basa principalmente en las investigaciones hechas por Allen Ezell, John Bear y el Dr. George Gollin de la Universidad de Illinois. Se recomienda la lectura de: Degree Mills: the Billion Dollar Industry that Has Sold Over a Million False Diplomas por Ezell y Bear. Asimismo, los trabajos sobre fraude académico que el Dr. Gollin tiene en internet: Diploma Mills: Updates on a Billion Dollar Fraud Industry (AACRAO Annual Conference, Abril, 2009). Tambien ver, en español, la presentación hecha ante el CCA por E. Arjona que se incluye en el CD que acompaña este informe

2 Se reportan mas de 200 agencias International Accreditation Commission for Postsecondary International Institutions, Council on Post-Secondary Accreditation, American Council of Private Colleges y Universities - APCU, Central States Consortium of Colleges y Schools - CSCCS

3 Ver entre otros: http://color-of-truth.com/WAUCFraudalert.pdf

4 Esta agencia es propiedad de Maxine Klein Asher quien la dirige desde su apartamento en Beverly Hills, Ca.

5 Se designan como universidades tipo vanity aquellas que, en letra de imprenta mínima por ejemplo, dicen ofrecer sus servicios a personas que para vanagloriarse quieren tener un copia ide

6 Ver http://www.google.com/search?client=safari\&rls=en-us\&q=table + signs + stands\&ie $=\mathrm{UTF}-$ $8 \&$ oe $=$ UTF -8

7 Justificación para otorgar el doctorado: 'Tengo más de sesenta año de experiencia en la industría de la aviación”. Traducción:' Desde los 6 años viajo en aviones'

8 Ver el caso Caplinger (fotografía arriba incluida) en Arjona, E. (2006) Fraude Académico. (CCA, Guatemala). Este powerpoint se incluye en el CD que acompaña este estudio.

9 Durante la reciente convención de la AACRAO (Asociación Americana de Secretarios Generales de Universidades y Directores de Admisión), el Dr. Gollin presentó una interesante exposición sobre los últimos acontecimientos en este tema. Por considerarlo de interés se incluye en el CD de este informe. El sr. Allen Ezell tambien presentó una ponencia sobre cómo identificar el fraude académico en registros de calificaciones, boletines, etc...

10 Se recomienda ver Gollins, G. Diploma Mills: Update on a Billion-Dollar Fraud Industry incluido en el CD que acompaña este informe.

11 Este imperio era manejado por Heide Lorhan, hija de Dixie Randock; Roberta Markishtum, anteriormente nuera de Steve Randock; Amy Hensley, cuñada de Roberta Markishtum; Richard Novak, novio en la secundaria de Dixie Randock; y Blake Carlson, íntimo de Richard Novak.

12 Iniciada en enero de 2005 con la participación de 8 agencias federales, estatales y locales estadounidenses. 
Invest. pens. crit. (ISSN 1812-3864)

Vol. 5, No. 1, enero-abril 2017

pp. $77-95$

13 Ver Gollin, G. Diploma Mills: Updates on a Billin-Dollar Fraud Industry. AACRAO Annual Meeting, April 14, 2009 incluido en el CD que acompaña este informe.

14 Ver en el CD adjunto: The real y the fake degree and diploma mills por Alan Contreras y George Gollin en CHANGE, marzo/abril de 2009. Alan Contreras es el administrador de la Oregon Office of Degree Authorization (Oficina para la Autorización de Títulos del estado de Oregón). Esta oficina mantiene el listado más completo sobre instituciones no acreditadas y agencias de acreditación de dudoso fiabilidad.

15 Por considerarlo de interés se han incluido listados de instituciones dudosas así como de agencias de acreditación no reconocidas por los diferentes gobiernos o estados y consideradas también de dudosa legitimidad.

16 En agosto de 2008, el Presidente Bush firmó la Higher Education Opportunity Act, ley que por primera vez ofrece una definición del término diploma mill.

17 Ver Contreras y Gollin. The real and the fake: Degree y Diploma Mills. Change, March/April 2009. p.42

18 Inclusive una posible vinculación con la notoria St. Regis University.

19 Mayor información se puede obtener llendo a

http:// forums.degreeinfo.com/showthread.php?t=27628. La fundación es sumamente quisquillosa sobre su identidad virtual y prohibe todo uso de cualquier información que se encuentra en su sitio web so pena de juicio legal.

20 Washington, Oregon, Nevada, Dakota del Norte, Dakota del Sur, Texas, Illinois, Maine, Nueva Jersey y Virginia. 